\title{
Human factors and ergonomics systems-based tools for understanding and addressing global problems of the twenty-first century
}

\author{
by Thatcher, A., Nayak, R. and Waterson, P.
}

Copyright, publisher and additional Information: This is the authors accepted manuscript. The final published version (version of record) is available online via Taylor \& Francis

Please refer to any applicable terms of use of the publisher.

DOI: https://doi.org/10.1080/00140139.2019.1646925 


\title{
Human factors and ergonomics systems-based tools for understanding and addressing global problems of the twenty-first century
}

\begin{abstract}
Sustainability is a systems problem with humans as integral elements of the system. However, sustainability problems usually have a broader scope than sociotechnical systems and therefore require additional considerations. This requires a fuller integration of complex systems understanding into the systems analysis toolset currently available to human factors and ergonomics. In this paper we outline these complex systems requirements necessary to tackle global problems such as sustainability and then assess how three common systems analysis tools (i.e. Accimap, System Theoretic Accident Mapping and Processes; and Cognitive Work Analysis) stand up against these revised criteria. This assessment is then further explored through applying two of these tools (i.e. Accimap and System Theoretic Accident Mapping and Processes) to a transnational food integrity system problem. This case study shows that no single systems analysis method can be used in isolation to help identify key insights for intervention and that new methods may need to be developed or existing methods need to be adapted to understand these dynamic, adaptive systems. The implications for the further development of systems analysis tools are discussed.
\end{abstract}

\section{Practitioner summary}

We assess the applicability of existing human factors and ergonomics systems-analysis tools for examining global problems and for identifying points to intervene in these systems. We comment on what extensions and further work will be required to enable human factors and ergonomics to intervene effectively.

\section{Introduction}

The latest report from the Intergovernmental Panel on Climate Change (2018) warns that we have twelve years to implement change on an unprecedented scale to avoid the worse effects of anthropogenic climate change on human wellbeing (http://www.ipcc.ch/report/sr15/). We have undeniably entered the Anthropocene (Crutzen, 2002; Steffen, Grinevald, Crutzen, \& 
McNeill, 2011); the geological age where human activity has had a measurable impact on geophysical and climate systems. The widespread burning of fossil fuels for energy has led to the increase of atmospheric carbon dioxide to levels that are measurably affecting climate change with even larger changes expected in the coming decades (Rosenzweig et al., 2008; Sobel et al., 2016; Steffen et al., 2018). The uncontained use of chlorofluorocarbons up until the 1990s led to serious damage to the ozone layer, the Earth's ultraviolet filter, and there is now evidence that chlorofluorocarbon levels are increasing once more (Montzka et al., 2018). Our lack of concern for our waste, especially plastics, has led to massive oceanic garbage accumulations such as the Great Pacific Garbage Patch which covers an area greater than 1.6 million $\mathrm{km}^{2}$ (Lebreton et al., 2018). Pollution now accounts for more than 9 million premature deaths worldwide (Landrigan et al., 2017). Excessive use of fertilizers to support intensive agriculture (amongst other anthropogenic nitrogen-fixing mechanisms) has resulted in the nitrogen eutrophication of riverine systems, coastal systems, and even oceans and has led to harmful algal blooms and biological dead zones (Sinha, Michalak, \& Balaji, 2017). There is also significant evidence that human activity is responsible for the sixth mass extinction event (Ceballos, Ehrlich, \& Dirzo, 2017). Climate change itself will lead to rising sea levels that will threaten coastal and island communities, droughts that will exacerbate food shortages, and lead to mass migration as people move to find habitable land (Rigaud et al., 2018) and wars as people fight over resources that will become more scarce (Kelley et al., 2015). This raises the question of the role of human factors and ergonomics (HFE) in ensuring human wellbeing and effectiveness in the face of these self-made threats.

\subsection{Global problems as complex systems}

Thatcher and Yeow (2016) have characterised these issues as complex, inter-related problems that have negative human and environmental consequences (see Table 1). They grouped these issues into three asymmetries: resource asymmetries (e.g. inequality in access to basic resources such as food, water, healthcare, etc.); waste accumulation and distribution asymmetries (e.g. carbon dioxide, heavy metals, plastics, etc.); and legislative asymmetries (e.g. worker protection, cultural protection, free speech, etc.). Table 1 gives illustrative examples of these three types of asymmetries as well as the human and environmental consequences that these asymmetries enable. It is also important to note that the relationships between these components are not simple; they are both inter-related and produce positive feedback loops that further exacerbate the asymmetries. For example, in poorer countries resources such as jobs, energy, healthcare, education, and sanitation are scarce. Those 
countries struggling with poverty, high unemployment, and poor healthcare and educational infrastructure are the most likely to be affected by climate change (Samir \& Lutz, 2017). However, they are also more likely to burn wood and fossil fuels leading to air pollution and deforestation.

[insert Table 1 about here]

In the future, disruptions to the global climate system will lead to significant global warming in many parts of the world (Foster, Royer, \& Lunt, 2017), droughts in some parts of the world and excessive rainfall in other parts of the world, more intense weather events (including hurricanes; Hansen et al., 2016; Sobel et al., 2016), and sea level rises threatening islands and coastal cities in particular (Chen et al., 2017; Garner et al., 2017). Not only will a warming planet lead to new thermal challenges, including disruptions to crop and livestock species that can withstand heat, but water resource challenges, increased diseases (Patz et al., 2014), and migration (Rigaud et al., 2018). Ominously, a warming global climate system also has positive feedback effect; i.e. greater evaporation and the melting of permafrost resulting in the release of more methane into the atmosphere. Unfortunately, this is only part of the picture as melting ice at the poles creates another positive feedback loop for global warming as well as changing the salinity of the oceans (Hansen et al., 2016).

These issues are tragic, frightening, and may even seem overwhelming, but what do they have to do with HFE? We argue that because these problems have been caused by humans (i.e. are anthropogenic), humans must also be the ones to find solutions through behaviour change and technology development. HFE is a systems discipline with the word "human" deeply embedded in our name and definition (Wilson, 2014). HFE is therefore significantly placed to contribute to finding solutions. Moray (1995) was one of the first people to systematically demonstrate the value that HFE could add to addressing the emergent problems of the twenty-first century. Moray (1995) summarised these as seven challenges: (1) water, (2) food, and (3) energy shortages, (4) pollution and waste, (5) urbanisation, (6) violence and terrorism, and (7) health and medicine. Thatcher, Waterson, Todd and Moray (2018) reviewed the work that had been performed in the HFE field since Moray's (1995) paper was published and noted that work addressing aspects of these seven challenges has steadily increased with new subfields such as human factors and sustainable development (Zink \& Fischer, 2013), green ergonomics (Thatcher, 2013), ergoecology (Garcia-Acosta et 
al., 2014), and even ergaianomics (Hancock, 2012) being proposed. Thatcher et al. (2018) noted that while the more pessimistic aspects of Moray's (1995) vision of the twenty-first century are yet to materialise (e.g. that industrially developed parts of the world would start to suffer from the same challenges as the industrially underdeveloped parts of the world), new challenges have also emerged. Of particular importance for this paper is the point raised by Thatcher et al. (2018) that these issues are complex and inter-related.

\section{Requirements for complex systems thinking tools in HFE}

Dekker, Hancock and Wilkin (2013) made it abundantly clear that if HFE is to address these global challenges, and we believe we must in order to avert a potential existential crisis, then this requires that our discipline embraces complex systems thinking. This means that the types of systems that are of interest in this paper require not just systems-thinking as envisaged by Wilson (2014), but complex systems-thinking. Salmon et al. (2017) noted that there is already an increasing need for complex systems-thinking in HFE and that our current methods and tools still require further methodological development. In particular, complex systems-thinking requires us to understand and incorporate concepts such as non-linear dynamics, emergence, adaptability, and self-organisation into our design and evaluation endeavours. Dekker et al. (2013) have emphasised that complex systems-thinking challenges the dominant epistemological stance of HFE which assumes that HFE studies closed systems, where all system elements can be known and measured. Like Dekker et al. (2013), we believe that complex systems-thinking is both necessary and long-overdue. In this section we introduce the lessons learnt from studying the functioning and resilience of ecological systems that can be applied to the most frequently used systems-analysis tools in HFE. In section 3 we provide a more detailed analysis of the frequently used systems-analysis tools to identify the strengths and limitations of these tools for addressing global challenges. In section 4 we summarise what methodological development that still needs to occur to make these tools complexity-ready and then in section 5 we give two examples of how these systems analysis tools need to be extended to understand a multinational food security issue.

\subsection{Hierarchical nested systems}

Simon (1962), in his classic paper The architecture of complexity, defined complex systems as being "composed of interrelated subsystems, each of the latter being, in turn, hierarchic in structure until we reach some lowest level of elementary subsystem" (p. 468). Evidence from 
multiple disciplines (Bronfenbrenner, 1979; Carayon et al., 2015; Clegg et al., 2017;

Costanza \& Patten, 1997; Gunderson \& Holling, 2002; Moray, 2000; Simon, 1962; Thatcher

\& Yeow, 2016) now characterises multiple interacting systems as forming a nested hierarchy with smaller, less complex systems being embedded within larger, more complex systems. Within the field of HFE, Moray (2000) represented various sociotechnical systems as being hierarchically nested (e.g. a physical layout system was embedded within a system of team and group behaviour, which was embedded within an organisational and management system, which was encapsulated within legal and regulatory systems, etc.). Rasmussen's (1997) risk management framework is also a form of nested hierarchy, although the emphasis is on the hierarchy rather than the 'nestedness' of systems. Thatcher and Yeow (2016) expanded on the notion of nested hierarchies in their sustainable system-of-systems (SSoS) model. Thatcher and Yeow (2016) stress that the important point to note about nestedness is that related (sociotechnical) systems are not simply "the context"; but rather encompassing systems provide the broader framework for understanding smaller systems. In turn, smaller systems provide the functional elements that allow encompassing systems to stabilise.

\subsection{Systems may have multiple human goals}

Numerous authors examining sustainable systems that include humans emphasise the need for the simultaneous achievement of multiple (human) goals (Altwegg, Roth \& Scheller, 2004; Elkington, 1998). Elkington's (1998) triple-bottom line of economic, social, and environmental goals is one example of multiple goals. Not only is the achievement of multiple goals necessary, but the different goals are interlinked and may even conflict. For example, the need for a worker to be employed under decent working conditions (i.e. a social goal) may conflict with the worker's need for employment regardless of the working conditions in order to bring home money to pay for food (i.e. an economic goal). Goals can also conflict between the different hierarchical levels. For example, the workers need for decent working conditions (i.e. a social goal) might conflict with the organisations need to make a profit (i.e. economic goal). Mauerhofer (2008) therefore calls for balance and prioritization of the goals. This takes the form of "burden of proof", where the sociotechnical system that draws from a particular goal also has the responsibility to show that the goals of other parts of the system are also balanced. To place this into the context; an organisation that needs to make a profit (i.e. an economic goal) must also show that the needs of employees for decent working conditions (i.e. the social goal) and the need to not destroy the natural environment (i.e. the environmental goal) are also met. Finally, it is important to note that 
these goals do not represent the only goals of a system. The goals referred to in this section are high level goals for the system-of-systems, rather the individual system goals.

\subsection{Natural lifespans of systems}

Costanza and Patten (1997) noted that no natural system is indefinitely sustainable. In fact, the natural lifespan of a system is determined to a significant extent on its relative position within the hierarchy of systems. Larger, more complex systems have longer natural lifespans than smaller, less complex systems that they encompass. Costanza and Patten (1997) noted that systems that last longer than their natural lifespan tend to become "brittle" and lose the flexibility to cope with changes to the external environment. Similarly, systems that don't reach their natural lifespan result in instability as interconnections collapse. There is therefore a finely balanced equilibrium in the lifespans of systems in the hierarchy. Thatcher and Yeow (2016) demonstrated how this applied to HFE systems (for example, a person-task-tool system will have a shorter expect lifespan than a person-job system). What is important to note is that an acknowledgement of natural lifespan properties introduces a time dimension into our understanding of systems and system interactions.

\subsection{Adaptive and self-organising systems}

Gunderson and Holling (2002) contend that all natural systems are really complex adaptive systems. While the concept of complex adaptive systems has already been introduced into the HFE literature (Carayon et al., 2015; Guastello, 2017; Karwowski, 2012; Walker et al., 2017) it has only been used to describe one of the properties of a complex system and not to explain the dynamics of adaptation. Beyond a certain level of complexity, natural systems exhibit self-organising adaptive properties. While the exact details of any self-organisation cannot easily be predicted, there are general phases that each complex adaptive system goes through during the adaptive process. Building on the lessons learnt from studying ecological systems, Gunderson and Holling (2002) argued that complex adaptive systems go through four "phases" of adaptation; exploitation, conservation, release, and re-organisation. Thatcher (2016) extended the SSoS model to show how HFE systems follow a similar adaptive cycle. The conservation phase is typically how we characterise most HFE systems in a state of equilibrium, although HFE has historically been most interested in systems in the release phase (i.e. systems where existing relationships start to break down).

\subsection{Emergence}


Complex systems also exhibit a property known as emergence (Dekker et al., 2013).

Emergence refers to behaviours, functions, or structures that "emerge" from system interactions that cannot be predicted by an analysis of the component parts (Bar-Yam, 2004). Part of the reason for emergence is that interactions in complex systems are not specifically top-down, horizontal, or bottom-up (Bar-Yam, 2004), neither are the relationships always linear (Dekker et al., 2013). Building from section 2.5, emergence is also a complex system property that accounts for self-organisation; patterns that emerge and define the behaviour of the components/agents within the system and the behaviour of the whole system (Ottino, 2004).

\subsection{Revolt and remember}

Not only are the phases through which a complex adaptive system passes predictable, but some of the interactions between the different levels in the hierarchy also produce predictable influences. Following from section 2.3 and section 2.4 on natural lifespans and complex adaptive systems, the rate at which a system will transition through the four phases will be dependent on its relative position in the nested hierarchy. Smaller, less complex systems will complete the adaptive cycle at a faster rate than larger, more complex systems. Furthermore, when a smaller, less complex system reaches the release stage these creative destruction changes provide an opportunity to influence changes in the larger, more complex systems. However, changes to smaller, less complex systems in the re-organisation phase will be restricted by the characteristics of larger and more complex systems systems, especially if those systems are in the conservation stage. Gunderson and Holling (2002) refer to these two processes as "remember" and "revolt" processes respectively. The revolt process, stimulates active change in the larger, slower, more complex systems and the remember process reduces the chance of smaller, faster, less complex systems from changing too rapidly and completely upsetting the existing equilibrium of the system-of-systems. In short, the ecological models show us that we can learn something about the nature of the "communication" between different system levels in the nested hierarchy.

\subsection{Summary: criteria for assessing the suitability of systems analysis tools for addressing global challenges}

In section 2 we have outlined a set of requirements for complex systems thinking tools in HFE. These requirements might be said to be generic to the vast majority of types of systems and domains we might come across in HFE (e.g. simple, closed-loop systems such as some 
types of human-machine interaction through to the complex open-loop systems commonly associated with transportation and healthcare; such as Proctor and Van Zandt, 2018; Baber et al., 2019). In addition to generic requirements, such as the need for tools to provide coverage of aspects of dynamic, adaptive, self-organising systems thinking, emergence, and the hierarchical nestedness of systems, we might also want to consider the extent to which these tools address the specific requirements of global, environmental systems which involve human and non-human agents/actors (e.g. plants, animals, and other ecosystem elements). Similarly, the 'revolt and remember' characteristics of global systems require that attention is paid to linkages between system elements and the types of network relationships which may exist in these types of systems. Finally, there is a need to consider the degree to which complex systems thinking tools have been applied to global challenges. Many of these systems thinking tools have focused, for example, on accidents and have provided retrospective analyses of the role played by human and organisational error in contributing to system breakdown (e.g. Underwood \& Waterson, 2014; Li et al., 2019). Accordingly, there is also a need to focus on the proactive and emergent aspects of global systems and how the human and non-human factors contribute to system functioning and evolution unfold over time. Table 2 summarises the generic HFE requirements (sections 2.1 to 2.6) alongside others which may be relevant to global challenges.

[insert Table 2 about here]

\section{Popular systems-thinking analysis tools in HFE}

There are already multiple possible tools available to the HFE discipline for understanding complex systems (Salmon et al., 2017). It is not possible to give a systematic review of all of the available tools. Instead, we have chosen to focus on three of these tools that are currently widely used in the HFE literature (Salmon et al., 2017; Waterson et al., 2017). In considering the dominant systems-thinking analysis tools in the HFE discipline we first give a short history and explanation of the main characteristics of each tool. We then look at the areas where each tool has been applied, focusing specifically on applications that might bear some resemblance to the sorts of global problems raised in this paper. We also consider whether each tool can be used to make predictions about possible future problems. Finally, we consider how each tool deals with adaptability and therefore the need for iterative design. 


\subsection{Accimap}

Accimap (Svedung \& Rasmussen, 2002) is an accident analysis tool that is based on Rasmussen's (1997) risk management framework. Essentially an Accimap provides a graphical representation of the causal relationships between actors in an accident scenario. The investigator typically starts by graphically representing the actors on an Actor Map according to their hierarchical levels. Rasmussen (1997) originally proposed six levels (i.e. government, regulatory bodies, the organisation, management, physical processes and staff, and equipment and surroundings) although the number of levels and the names of the levels might vary depending on the requirements of the accident scenario. The actors are mapped onto the hierarchy and then links are made between the actors to show their structural relationships. The next step is to map the errors and show the links between the errors and the various actors (i.e. Info Maps). The errors are usually first mapped at the level of physical processes and the staff directly involved in the accident. After this, the analyst tries to establish the causal relationships between the actors and processes that contributed to the accident (i.e. Conflict Maps). The analyst must be as exhaustive as possible with regards to all the errors even if they are not apparently linked to the accident. Generic Accimaps can also be created to look at groups of accidents in order to identify common underlying relationships.

Accimaps have been applied in a wide variety of contexts. Waterson et al. (2017) identified ten different accident domains in which Accimaps had been applied from 2000-2015: manufacturing; nuclear; aviation and aerospace, emergency response services; civil engineering; oil and gas; public health; transport systems (especially rail and road systems); outdoor recreation; and policing and security. Of all these domains, the work on public health probably comes closest to the types of global problems that Moray (1995) was referring to. Woo and Vicente (2003) used the Accimap tool to understand the errors involved in two water-borne disease outbreaks. Cassano-Piche, Vicente, and Jamieson (2009) used the Accimap tool to understand the underlying causes of the bovine spongiform encephalopathy (BSE) outbreak in the UK in 1986. Nayak and Waterson (2016) used the Accimap tool to understand the systemic factors in two outbreaks of E. Coli in the UK, one in 1996 and another in 2005. Tabibzadeh and Meshkati (2015) used the Accimap tool to analyse the Deepwater Horizon oil spill and Tabibzadeh et al. (2017) used the Accimap tool to analyse the Aliso Canyon gas leak in 2015. While these studies investigated very specific incidents they were useful in uncovering the important contributory roles played by regulators and 
governments that have far broader applications. In addition, Tabibzadeh et al. (2017) emphasised the role of Accimap analyses in reducing the risks to public health and the more generally to the environment. The best example of a study that uses Accimap to examine the types of global issues envisaged in this paper is Nyman and Johansson's (2015) work examining the flooding of a railway tunnel in Sweden as a result of climate-change. Nyman and Johansson (2015) praise the Accimap tool for being able to handle decision-making that is distant in time and location which are important considerations for addressing global problems.

Accimap has primarily been used to analyse the systemic causative factors of past accident and incident events. Nayak and Waterson (2016) warn against the "postdictive" (as opposed to predictive) properties of Accimap analyses which may lead to a hindsight bias. To date the Accimap tool has only been used to examine the static consequences of single events (or in the case of a generic Accimap, an aggregation of single events) rather than the dynamic nature of systems. Nayak and Waterson (2016) also warn that despite the claim that Accimaps look at dynamic systems, they actually encourage the analyst to consider a linear view of systemic processes rather than a non-linear, adaptive approach. Further, Waterson et al.'s (2017) and Filho et al.'s (2019) in-depth analysis of Accimaps and the STAMP methodology suggests that there are reliability and validity issues with many of the published Accimap analyses. On a more positive note, Nayak and Waterson (2016) argue that Accimaps encourage HFE to look at broader social and political processes that impact on accident outcomes.

\subsection{Systems-Theoretic Accident Model and Processes (STAMP)}

The Systems-Theoretic Accident Model and Processes (STAMP) tool is another accident analysis tool built on Rasmussen's (1997) risk management framework (Leveson, 2004). Leveson (2004) essentially sees accidents as a system control problem and design interventions should concentrate on providing system constraints to ensure safe operation. Similarly to an Accimap, analysis includes mapping agents onto a hierarchical control structure (essentially Rasmussen's (1997) risk management framework, although with a concentration on the higher levels in the hierarchy). What differs from an Accimap though is that rather than only linking the actors/agents through structural relationships they are also annotated according to the constraints that they place on the system. Leveson (2004) provided a generic control structure model to guide the analyst. Similarly to Accimaps the relationships 
between hierarchical levels are characterised as downward control (control constraints) and upward information sharing (information constraints). The next step is to classify each element in the control structure according to Leveson's (2004) classification of flawed control (e.g. inadequate enforcement of safety controls, communication flaw, or incomplete process model).

The STAMP tool has also been used in a wide variety of contexts, although almost always to analyse accidents or safety incidents. Application areas have included air traffic control (Fleming et al., 2013), railway accidents (Ouyang et al., 2010), and military accidents (Rong \& Tian, 2015). The STAMP tool has been particularly useful in specifying the role of higherlevel agents such as governments and regulators in safety incidents. The study that most closely aligns to the types of global problems envisaged by this paper is Rosewater and Williams' (2015) investigation of a lithium-ion energy storage system. The system investigated by Rosewater and Williams (2015) was relatively small, although it is fairly easy to see how this type of analysis might be scaled-up to larger energy grid systems. In general though STAMP has been characterised as difficult to use and the graphical outputs have been difficult to interpret (Underwood, Waterson, \& Braithwaite, 2016). In addition, Salmon, Cornelissen, and Trotter (2012) have noted that STAMP cannot ostensibly take uncontrollable aspects of the external environment (e.g. weather) into account.

STAMP has been used for predictive purposes both as a preventative tool (Lu et al., 2015) and as a predictive tool (Fleming \& Leveson, 2016; Ishimatsu et al., 2014; Leveson, 2015; Rong \& Tian, 2015). STAMP also specifically conceptualises systems as needing to be kept in dynamic equilibrium and not as static entities (Leveson, 2004). Despite the positive properties of STAMP, significant amounts of detailed (often expert) data are required to produce a meaningful understanding of the constraints. STAMP is also limited to accident or safety scenarios, rather than to a general understanding of normal operations.

\subsection{Cognitive Work Analysis (CWA)}

Cognitive Work Analysis (CWA) is a collection of analysis tools for complex sociotechnical systems to determine how work is actually done (descriptive) and how it could be done (formative). CWA is a set of five analysis phases that can be used relatively independently of one another (Vicente, 1999). The five phases of the CWA framework are: (1) work domain analysis (WDA); (2) control task analysis (ConTA); (3) strategies analysis (StrA); (4) social 
and organisation cooperation analysis (SOCA); and (5) worker competencies analysis. Each phase might be used for different purposes. In a WDA, Rasmussen's (1985) abstraction hierarchy levels are used to develop a description of the work domain under consideration that is independent of a specific context (Stanton et al., 2013). The hierarchical levels are not based on the complexity of external physical features (as with the risk management framework) but rather on the functional complexity of the task based on a means-ends continuum (Rasmussen, 1985). Additionally, the interactions between different functional levels are not based on control and communication but on means-ends links. The WDA essentially defines the constraints of the system imposed by the cognitive limitations of the human operator. The WDA is the most frequently used phase of CWA.

While the WDA is intended to be context-independent the ConTA phase specifically focuses on the primary or recurring tasks to represent the activities that must be performed to meet the requirements of the WDA. The ConTA is usually visually represented as contextual activity templates (Naikar, Moylan, \& Pearce, 2006) that have work situations on one axis and work functions on the other axis. The contextual analysis templates can also be examined through a decision-making lens by using a decision ladder (Vicente, 1999). The StrA typically uses information flow maps to look at all the ways that each activity can be performed (drawing the activities from the ConTA). SOCA is used to identify the relationships between the human and non-human agents in a system and to determine how tasks might be appropriately distributed. According to Stanton et al. (2018), the first step in SOCA is to define all the agents and their roles. The second step is then to map the roles across the different tasks to determine redundancies and gaps for agents and their roles. This can be performed on a contextual analysis template to achieve a graphical representation called a SOCA-CAT or on the decision ladder to achieve a graphical representation called a SOCA-DL. The fifth phase of CWA is a worker competencies analysis. This uses Rasmussen's skills, rules, and knowledge typology to identify the relevant cognitive abilities required for task performance. Worker competencies analyses are rarely used in CWA.

CWA is not meant to be prescriptive with regards to design options. Instead, CWA intends to leverage the flexibility and adaptability of the humans in the system within the constraints of the entire system. CWA was initially developed to analyse work in nuclear power plants but has now been used in many other areas of application including interface design (Jenkins et al., 2010), military systems (Naikar et al., 2006), air traffic management (Lundberg et al., 
2018), rail and pedestrian systems (Read et al., 2016), healthcare (Jiancaro, Jamieson, \& Mihailidis, 2014), urban planning (Stevens, Salmon, \& Taylor, 2018), and power grid management (Hilliard, Tran, \& Jamieson, 2018). Most of the CWAs have involved fairly contained sociotechnical systems of operation, but there are a few studies that demonstrate the potential to look at larger, more complex systems. Stevens et al. (2018) conducted a WDA as part of a needs analysis for an active urban transport infrastructure. The output of the WDA was a set of design parameters that extended beyond the original design purpose (i.e. the design of pedestrian pathways). However, Stevens et al. (2018) still needed to complete additional phases of the CWA to define the tasks and roles of the different agents in the system. Hilliard et al.'s (2018) study also consisted of a WDA, including abstraction hierarchies, examining energy grid operations. The WDA covered a fairly broad geographical area and also included aspects such as dispersed transmission lines and transmission stations, as well as the role of the weather in their system. Hilliard et al. (2018) argued that the analysis could be extended to larger more complex energy grid systems and to test out new forms of energy grid systems such as "smart" grids. Chauvin et al. (2015) actually applied CWA to look at designing "smart" grids. While the CWA produced many new design recommendations, Chauvin et al. (2015) focused on design recommendations for an ecological 'smart' meter interface rather than on geographically broader application areas.

Allison and Stanton's (2018) study on design recommendations for fuel-efficient driving using CWA has important implications for addressing one of the global problems; climate change. Allison and Stanton (2018) identified a range of different interface design, behaviours, legislation, and infrastructure design aspects that are important to support ecodriving. Carden et al. (2017) also demonstrated how WDA could be used to evaluate the structural integrity of legislation. While the context was not specifically related to one of the global issues identified in this paper (their context was adventure sports legislation), their study does provide a broadened scope for CWA. Finally, Walker, Beevers, and Strathie (2018) used CWA to look at how civil infrastructure would stand up to extreme weather events. Using whole towns as example systems, Walker et al. (2018) used WDA to model the vulnerabilities from a 1 in 200 year flood event. Walker et al.'s (2018) work has clear and important links with supporting adaptation measures to the looming global problems identified in this paper. 
There are numerous examples of CWA phases being used as prospective tools to identify possible future designs (Chauvin et al., 2015; Naikar et al., 2006; Lundberg et al., 2018; Read et al., 2015; Stevens et al., 2018; Walker et al., 2018). WDA in particular, because it is context-independent, facilitates the development of graphical representations that can help the analyst understand the design implications for future broader systems, functions, and system interactions. As for attempts to incorporate dynamic processes into the models, Hilliard et al. (2018) made some initial attempts. They did, however, emphasise that further extensions to WDA would be required to represent the dynamic nature of many work situations. Naikar and Elix (2016) argue that CWA struggles to deal with the adaptations necessary in dynamic systems because CWA supports adaptation of the behaviours of actors but not necessarily the structure of work relationships. Instead, Naikar and Elix (2016) proposed an extension to CWA, called a Work Organization Possibilities (WOP) diagram, in order to support actors to integrate their behaviour adaptations with the organisational structural possibilities. However, a WOP diagram presupposes that the different possibilities for work organisation are already known and this constrains the types of adaptations which are possible. In the types of problems envisaged in this paper, the range of organisational possibilities and all the constraints on the various possibilities are not necessarily known. Further adaptations to WOP diagrams may therefore be necessary.

\section{Suitability for analysing global problems}

From the discussion in section 3 the complex systems requirements are mapped against the qualities of the systems analysis tools in Table 3. Table 3 compares the ability of each of the HFE systems' analysis tools to incorporate the complex systems-thinking qualities and therefore to be good candidate analysis tools for understanding global systems problems. It is evident that all tools demonstrate at least some potential (especially goals 1-5 in Table 2) to be used for understanding and intervening to address global challenges. Accimap is probably the easiest tool to use, but has limitations when it comes to investigating adaptive systems and testing predictive solutions. In addition, Nayak and Waterson (2016) have expressed concerns with the reliability and validity of Accimaps. To be fair though, the reliability and validity of STAMP and CWA have not been systematically assessed.

[insert Table 3 about here] 
With the exception of CWA, Accimap and STAMP did not deal adequately with the fact that complex systems are not static, but dynamic. Ottino (2004) noted that engineered systems assume a static end-design, but that complex systems require adaptation and self-organisation as essential qualities. Dekker et al. (2013) went further to suggest that the dominant scientific paradigm of HFE was unsuited to deal with complex systems because the emphasis has been on studying closed systems. CWA has the potential to deal with dynamic action through WOP diagrams, but current complex system's tools in HFE clearly require further extension in this regard. None of the tools reviewed incorporated emergence. It may very well be the case that it is a principled decision not to include emergence in systems analysis tools, especially as it is virtually impossible to design for eventualities that cannot be foreseen. However, emergence is a key attribute of complex systems and we would argue that systems that do not account for emergence will become brittle and thereby unsustainable.

None of the tools describe the relationships between different hierarchical system levels specifically in terms of Gunderson and Holling's (2002) "revolt" and "remember" processes. STAMP come closest by describing the "downward" relationships as primarily being controls (through laws, regulations, rules, and instructions). The abstraction decomposition space in CWA also provides a form of nested hierarchical systems (although for a single system) but once again the relationships between the "levels" are considered only in a top-down "control" manner. None of the tools characterise "upward" relationships as revolt processes. This may be because the tools emerged from a human control perspective which attempts to resolve control issues rather than embrace system perturbations.

With these limitations and potentials in mind, next we give an example of how we might use two of the systems analysis tools to highlight different aspects of complex systems thinking tools. We chose two specific methods (Accimap and STAMP) rather than others (e.g. CWA or FRAM - Hollnagel, 2012) largely because of space and brevity considerations within the paper. We also note that Accimap and STAMP also represent some of the most popular and common ways of using systems analysis tools to analyse complex, sociotechnical systems and are often used for comparative purposes (e.g. Salmon et al., 2012; Underwood \& Waterson, 2014).

\section{Applying systems-based HFE tools to global problems: a food integrity example}




\subsection{Background (Elliott, 2014)}

The 2013 horsemeat scandal was a major food fraud incident that was felt across multiple transnational boundaries. Foods advertised as containing beef were found to contain improperly declared horsemeat $-100 \%$ horsemeat in some cases (BBC News, 2013). A few products also contained other undeclared meats such as pork. These foods were distributed all across the Irish and British food supply chains, and had links to 13 other European countries. Although not a health issue, this incident highlighted the lack of traceability in the food supply chain, and raised concerns about the possibility of undetected harmful (e.g. performance enhancing drugs used in racehorses) or religiously-sensitive (e.g. pig products) ingredients in imported foods. This led to public outrage and panic in the United Kingdom (UK) as a vast majority of the British and Irish consumers do not eat horsemeat. The impact of this incident prompted an international rethink of the robustness of the global food system - one such rethinking strategy led to the Elliott Review (2014).

Food fraud costs the United Kingdom (UK) food industry nearly $£ 12$ billion annually. Routine assessment of product integrity is often limited to visual and olfactory senses and use of artefacts, such as verbal reminders, or verbal and written guidance, leading to weakened governance and audits of non-compliant behaviours across the supply chain. Financiat constraints and meeting evolving consumer demand means food fraud-orientated "problem ownership" lies with multiple actors. The influence of psychological, societal, and organisational factors on the motivation to commit food fraud is poorly understood. Each year around $27 \%$ of $U K$ consumers experience at least one issue related to food fratd such as swapped ingredients in food and/or misleading labelling (Woods, 2017). Food and drink is a $£ 200$ billion industry in the UK and due to the complexity of its operational structure (Nayak \& Waterson, 2016; Woods, 2017), it is vulnerable to a wide range of fraudulent activities. Indeed, only $38 \%$ of UK consumers have confidence in the British food supply chain, $12 \%$ have confidence in the European food chain, and 7\% have confidence in the global food ehain (Elliott, 2014; Woods, 2017).

The current approach of coercing food businesses to comply with national food safety standards (e.g. through regulations) fails to motivate problem ownership and thus fails to address food fraud problems. Recommendations made by the Elliott Review (2014) highlight the importance of going beyond regulatory measures to develop effective barriers, both nationally and internationally, and deter fraudulent behaviours without burdening food 
businesses with additional regulations and policies (Elliott, 2014). However, a systems approach is needed to establish the structure and functioning of the food system as recommended in the Elliott Report (2014), to help identify, develop, and improve novel methods to deter fraudulent activities.

\subsection{Accimap and STAMP analyses}

\subsubsection{Accimap analysis}

The Accimap resulting from the analysis of the Elliot (2014) Review is presented in Figure 1. The events leading up to the Elliott (2014) Review such as the large-scale public outrage and loss of market share arising from the lack of traceability due to the complexity of the food supply chain, acted as reference points for the analysis at the consumer level as well as the workplace, organisational, and government levels of the food system. Although the scandal was labelled as a horsemeat scandal, the systems analysis carried out reinforced the conclusion from the Elliott (2014) Review that an accumulation of similar enabling factors led to many other food fraud incidents in the UK and Europe. The 'enabling factors' are factors that make it possible (or easier) for individuals or teams to change their behaviours or their environment (Porter, 2016). The enabling factors included in Figure 1 highlight the failures across various systemic levels throughout the European and British food systems. The enabling factors also helped analyse interactions between these factors across and within systemic levels, and identified emergent behaviours throughout the whole system.

The focus of the Accimap analysis was on two components: (1) underestimation of the risks and impact of food fraud and (2) lack of problem ownership by food businesses and the government. The Accimap also establishes that food businesses alone were not to blame for food fraud incidents - an absence of an adequate number of deterrents (e.g. disagreements between local councils and the Food Standards Agency and undermining risks associated with food fraud) also acted as enabling factors for food businesses to commit fraudulent activities. Two enabling factors were identified at the national government level - this level involved ministerial positions and was responsible for formulating regulations with the European Union. The non-ministerial government department consisted of stakeholders who were responsible for adapting EU regulations into UK specific laws - six enabling factors were identified at this level. The next level (local councils) consisted of stakeholders responsible for carrying out inspections and enforcement actions within local counties across 
the UK - three enabling factors were identified at this level. The subsequent two levels (i.e. management and shop-floor employees) consisted of stakeholders from food businesses eleven and two enabling factors were identified respectively in these levels. The consumer level highlights five consumer-related enabling factors that lead to food fraud incidents.

Lack of problem ownership is a key theme of the factors identified at the national government level - factors such ineffective cooperation with the European commission and an uncertain political climate highlight ministers' prioritisation of personal and political interests over public interest. A plausible cause for this is an underestimation of the risks of food fraud by stakeholders who do not understand the functioning of the food system. The key theme deduced from the identified enabling factors in the non-ministerial government department level is prioritising food safety over food fraud, and treating the two as mutually independent events. Unpreparedness towards food fraud and conflicting priorities at the ministerial level (e.g. prioritisation of exports) contributed to treating food safety and food fraud as events independent of each other. This had an impact on the local councils. The involvement of multiple stakeholders with different priorities higher up the hierarchical level in the UK food system led to disagreements and confusion within local councils. The heavy workload within local councils also led to a lack of a detailed understanding of the food supply chain due to a lack of time. All these factors contributed to prioritising food safetyrelated enforcement over identifying food fraud. The complexity of the food system and the involvement of multiple stakeholders with conflicting priorities played a key role in enabling fraudulent activities within food businesses.

Prioritisation of profit generation and a short-term sales focus played a key role in food businesses committing food fraud-related activities. Although none of the food businesses that committed food fraud intended to harm their consumers, food fraud evolves into food crime when rogue groups knowingly carry out organised activities to deceive those purchasing their food products (Elliott, 2014). Factors such as mislabelling, threatening management and shop floor employees, providing incentives for committing illegal acts, and establishing a culture of fear within the business highlight the extent of organised illegal activities carried out by food businesses. Advertising extensively, with the intention to overwhelm customers with information, was also identified as an enabling factor that facilitated food fraud through the intentional deception of consumers - for example, unnecessary visual information such as bold text advertising of what the product looks like 
(e.g., 'the fresh look' of a product) and olfactory information such as bold text advertising of what the product smells like (e.g., 'smells like childhood'). Enabling factors identified at the "management" and "shop floor employees" levels in Figure 1 highlight the emergence of fraudulent behaviours and activities within organisations due to the presence of enabling factors higher up the hierarchical chain. Emergent behaviour in this context is defined as fraudulent behaviour(s) practiced by food businesses and its stakeholders, evolving from the relationships (interactions) between the enabling factors located throughout the food system. This implies that emergent behaviour cannot be predicted by analysing individual components of the food system, and can only be managed, predicted, or controlled by understanding all the components and their relationships.

A critical finding of the Accimap analysis is the unintended role that consumers also play in encouraging fraudulent activities within food businesses. Consumers often tend to demand high quality, variety, and low-cost or affordable food - food businesses' desire to meet these contradicting demands in order to maximise sales, coupled with the presence of other enabling factors (mentioned above) promotes illegal activities leading to food fraud and other food crimes. The analysis also highlights consumers' hesitance to report food fraud incidents. Thus, food fraud is both under-reported and goes undetected.

[Figure 1 about here]

\subsubsection{STAMP method analysis}

Figure 2 displays a STAMP analysis (adapted from Nayak \& Waterson, 2019) of the UK food system - it identifies the controls and constraints in the higher levels of control within the UK food system to help prevent food fraud and ensure food safety. A STAMP analysis helps in understanding how and why unsafe decisions were made (Leveson, 2004) within a complex system. Although the model in Nayak and Waterson (2019) was analysed from a food safety perspective, the aim of the STAMP analysis was to develop an understanding of the UK food system. An adapted version of the model has been utilised in this paper due to the relevance of the food system under analysis. As seen in Figure 2, there are two hierarchical control structures: (1) food system development (i.e. processes and stakeholders involved in the food manufacturing/growing phase); and (2) the food system operation (i.e. processes and stakeholders involved in the sales, distribution, and inspection of food and food premises). The STAMP analysis identifies and addresses potential and existing flaws in the 
control and feedback structures of food systems, and provides regulators, policy-makers and reformers with the ability to design a well-structured food system with adequate controls and constraints in place to prevent food fraud and food crime.

The STAMP analysis emphasises the control constraints provided by the higher levels in the hierarchy to the lower levels in the system (e.g. developing legislation and codes of practice, providing guidance and advice, conducting inspections and audits, administering penalties, developing company policies, and providing training and supervision) and the higher levels receiving feedback from the lower levels in the system (e.g. complaints and suggestions, incidents and near-misses, public and employee opinions, and production data). However, without detailed data on the thinking and reasoning behind behavioural decision-making it is difficult to determine where constraints and feedback has failed using Leveson's (2004) classification of flawed control.

[Figure 2 about here]

An additional strength of the STAMP analysis is that it provides a detailed account of the various stakeholder groups and subsystems involved in the UK food system, their interactions and place within the wider international context. The STAMP analysis also facilitates crosslevel or 'mesoergonomic' interactions to be made explicit. Karsh et al. (2014) defined mesoergonomics as "an open systems approach to ergonomic theory and research whereby the relationship between variables in at least two different levels or echelons is studied, where the dependent variables are human factors and ergonomic constructs" (p. 46). In terms of Figure 2, for example, the STAMP analysis highlights links between stakeholders in upper ('blunt end') levels of the food system (e.g. Government agencies such as the UK Standards Agency) and lower ('sharp end') levels (e.g. in this case front-line employees and local farmers).

\subsubsection{Discussion - issues from the two systems analysis techniques}

Complex food systems can be defined as systems that comprise of a number of strongly interacting entities, processes, or agents, the understanding of which requires the development, or the use of new scientific tools, nonlinear models, out of equilibrium descriptions, and computer simulations (Rocha, 1999). Although some food systems might appear to be simple (pseudo-simple), it is important to remember that "complexity is not 
located at a specific, identifiable site in a system (Cilliers, 1998, p. 2) - thus, in reality, all food systems are complex systems as they contain a large number of inter-related elements (Cilliers, 1998; Nayak \& Waterson, 2016) which interact in a complex manner to lead to increased possibilities of outcomes than can be actualised (Luhmann, 1985). Pennington (2003) argues for the need to adopt a systems approach (and systems thinking) to ensure food safety. He uses the concept of a systems based approach to compare food poisoning outbreaks to the Chernobyl, Piper Alpha, and railway accidents in Ireland and Britain (Nayak \& Waterson, 2016).

Thus, since the food system is tightly interwoven globally and the pace of change is increasing continuously, it is important to be system-wise, and compare the two systems analysis techniques used in this section with the characteristics of complex systems. Following from Table 2 and Table 3 it is clear Accimap and STAMP do not normally capture complex systems thinking requirements such as the dynamic, adaptive, and self-organising aspects of these types of systems. While the analyses can easily identify hierarchies, the nestedness of the hierarchies is more obscure and the mapping of the different hierarchical levels also does not incorporate thinking about the openness to system change and any resistance to system change in smaller systems. The analyses outputs tend to capture the complex system "as if" it were a cross-section in time, even though temporal components are deeply embedded in the outputs. In addition, Table 4 highlights aspects of complex systems that each systems analysis technique covers, but does so in slightly different ways.

[insert Table 4 about here]

It is also evident that the UK food system in its present state is not particularly adaptive. This might explain the high number of food fraud incidents without a sustainable solution. Instead, there as a "blame-the-culprit" approach that does not help reduce food fraud incidents. The regulatory framework attempts to manage the risk through the development of more complex policies (this may be an example of a top-down "remember" process preventing the system from changing too much). In fact, one would be more likely to see adaptive "revolt" properties if the analysis included how perpetrators responded to policy development. However, the analysis necessarily followed the available data (i.e. the Elliott (2014) Review) which did not include these types of reactive/interactive components. Additionally, the analysis emphasizes unidirectional relationships rather than multidirectional relationships. 
For example, climate change would surely play a role not only in agricultural production, but also with factors such as delays/cancellations in transportation leading to food becoming unsafe for consumption. This would, in turn, have an impact on stakeholders' attitudes and behaviour (e.g. looking for alternative/cheaper resources and substitute ingredients, or adding preservatives to food). Neither the Accimap nor the STAMP analysis highlights these multidirectional or emergent properties.

Also not included in Table 4 is the fact that neither Accimap nor STAMP enabled predictive assumptions, captured dynamic, adaptive, or self-organising components of the system, or considered the pacing of system transitions. This points to new tools or representations being required to fully map these types of complex systems.

\section{Conclusions and ways forward}

Following Waterson et al. (2017; 2015), we would argue that what is needed is a re-mixing of systems analysis tools, taking parts from multiple tools both within and outside the HFE domain for a more complete understanding of complex adaptive systems. The Accimap and STAMP analysis in section 5 shows us how different tools enable us to uncover different aspects of the system functioning, but it also shows us that further tools are still required. None of the tools were able to address all of the aspects required of complex system's thinking within a global context on their own. We would concur with Salmon et al. (2017) that there are no current HFE complex system tools that incorporate all the necessary system properties and in particular, the ability to dynamically track changes, although attempts are being made with CWA (Naikar \& Elix, 2016). Recently Dallat, Salmon, and Goode (2018) developed a new tool called NET-HARMS for predicting risks rather than simply analysing risks. NET-HARMS is based on Hierarchical Task Analysis and many of the visual outputs have a similar properties to CWA and Accimap. This might assist with identifying emergence which is absent from the existing toolset. There are also complex systems models from outside the HFE literature that look at adaptive change in sociotechnical systems. For example, Clegg et al. (2017) developed a tool called PreMiSTS used to predict malfunctions in sociotechnical systems. PreMiSTS promises to be particularly useful in handling iterative design required by complex adaptive systems.

Actors or agents in the system are most often characterised as human or technological artefacts (Stanton et al., 2013). This is inevitable since the systems analysis tools have been 
developed to examine sociotechnical systems. However, as shown in section 3 it is also possible to define other ecological artefacts such as the weather (Hilliard et al., 2018; Walker et al., 2018). For addressing global problems this will need to be taken further to define other types of non-human ecological artefacts such as plants and animals, ecological patches, ecosystems, biomes, and the biosphere (depending on the boundary of the analysis) that each influence and are influenced by the sociotechnical system/s.

A further point of extension is to carefully consider the relationships between the nested hierarchical levels. Existing HFE systems analysis tools tend to describe the relationships as either controlling or as simple one-way or two-way communication. However, complex systems thinking from a global sustainability perspective provides a far more nuanced understanding of the hierarchical relationships, involving clearly defined roles for the different relative placements of elements within the nested hierarchy (of systems). From a global sustainability perspective, these relationships are characterised as revolt and remember processes which attempt to influence specific outcomes. Further work is required to firstly identify whether such relationships exist in eco-sociotechnical systems and secondly, if they do exist, to understand how they might be influenced through design. Thatcher and Yeow (in press) have begun the exercise of mapping the revolt and remember processes onto design intervention possibilities. For example, they have suggested that bottom-up interventions would be easier to implement (because they involve simpler, less complex systems) but one may need many interventions or multiple iterations before changes are seen in the larger, more complex systems. Similarly, top-down interventions would be more difficult and slower to implement but could have cascading effects to many smaller, less complex systems.

System adaptation and self-organisation is a characteristic of all complex systems, yet existing HFE system analysis tools fail to take these characteristics into account. System analysis tools that enable design for system resilience are now required. However, resilience as it is currently defined within sociotechnical systems thinking has a different interpretation to resilience in ecological systems. Resilience in sociotechnical systems refers to the ability of the system to cope with perturbations and return to the same state. In ecological terms this is referred to as stability (Gunderson \& Holling, 2002). Ecological system resilience refers to the persistence of relationships between system elements, although not necessarily with the same combinations or patterns (Gunderson \& Holling, 2002). For global problems a more ecological interpretation of resilience is required. 
The types of complex systems that we have envisaged in this paper are extensive by traditional HFE standards and yet there are obvious ways in which HFE researchers and practitioners can help others understand these systems to identify points of intervention. However, the sizes of systems that include global challenges pose a potential limitless boundary problem (i.e. where does one draw the boundaries of the system analysis?). Thatcher and Yeow (2018) consider this limitless boundary problem and recommend Stakeholder Salience Theory and Network Theory as potential candidate theories to help resolve the limitless boundary problem while still identifying the relevant systems of influence.

A final point, and an important one in terms of what might be a gap in our understanding of how complex global systems function, is that most current systems thinking tools in HFE provide a very static account of how systems function. Typically, large global catastrophes are the result of degradation of the system over significant periods of time (and arguably, there is also an indication of degradation over time in the complex systems currently studied in HFE). In the words of Dekker (2011) systems often "drift into failure" and the processes involved in system malfunction may take years, and in some cases decades, to manifest. Often the process of large-scale failure involves an 'incubation' period (Turner, 1978) where failure takes time to build and gain momentum. Likewise, global systems may 'wax and wane' in terms of the degree to which they learn about failure mechanisms and as a result, put in place compensatory measures. Current systems thinking tools need to address this temporal dimension and factor this into a more predictive, and in some case, proactive approach towards systems failure, relapse, and recovery (Grant et al., 2018).

\section{References}

Allison, C. K., \& Stanton, N. A. (2018). Using cognitive work analysis to inform policy recommendations to support fuel-efficient driving. In N. A. Stanton (Ed.), Advances in human aspects of transportation (pp 376-385). Springer Nature, Cham.

Altwegg, D., Roth, I., \& Scheller, A. (2004). Monitoring sustainable development (MONET):

final report - methods and results. Swiss Federal Statistical Office, Neuchâtel. Ashby, W.R. 1956, An Introduction to Cybernetics. London: Chapman \& Hall. 
Baber, C., Golightly, D. and Waterson, P.E. (2019, in press). Quantifying complex dynamic systems: the cybernetic return. Applied Ergonomics, in press.

Bar-Yam, Y. (2004). A mathematical theory of strong emergence using multiscale variety. Complexity, 9(6), 15-24.

Bronfenbrenner, U. (1979). The ecology of human development: Experiments by nature and design. Harvard University Press, Cambridge, MA.

Carayon, P., Hancock, P., Leveson, N., Noy, I., Sznelwar, L., \& Van Hootegem, G. (2015).

Advancing a sociotechnical systems approach to workplace safety-developing the conceptual framework. Ergonomics, 58(4), 548-564.

Carden, T., Goode, N., Read, G. J., \& Salmon, P. M. (2017). Sociotechnical systems as a framework for regulatory system design and evaluation: Using work domain analysis to examine a new regulatory system. Applied Ergonomics, in press. DOI 10.1016/j.apergo.2017.02.019.

Cassano-Piche, A. L., Vicente, K. J., \& Jamieson, G. A. (2009). A test of Rasmussen's risk management framework in the food safety domain: BSE in the UK. Theoretical Issues in Ergonomics Science, 10(4), 283-304.

Ceballos, G., Ehrlich, P. R., \& Dirzo, R. (2017). Biological annihilation via the ongoing sixth mass extinction signaled by vertebrate population losses and declines. Proceedings of the National Academy of Sciences, 114(30), E6089-E6096.

Chauvin, C., Rauffet, P., Tréhin, M., Berruet, P., \& Lassalle, J. (2015). Using cognitive work analysis to design smart grid interfaces. In D. de Waard, K. A., Brookhuis, A., Toffetti, A. Stuiver, C. Weikert, D. Coelho, ... \& N. Merat (Eds.) (2016). Proceedings of the Human Factors and Ergonomics Society Europe Chapter 2015 Annual Conference. Available from http://hfeseurope.org.

Chen, X., Zhang, X., Church, J. A., Watson, C. S., King, M. A., Monselesan, D., ... \& Harig, C. (2017). The increasing rate of global mean sea-level rise during 1993-2014. Nature Climate Change, 7(7), 492.

Cilliers, P. (1998). Complexity and postmodernism. Understanding complex systems. London: Routledge.

Clegg, C., Robinson, M., Davis, M., Bolton, L., Pieniazek, R., \& McKay, A. (2017).

Applying organizational psychology as a design science: A method for predicting malfunctions in socio-technical systems (PreMiSTS). Design Science, 3, E6.

doi:10.1017/dsj.2017.4 
Costanza, R., \& Patten, B. C. (1995). Defining and predicting sustainability. Ecological Economics, 15(3), 193-196.

Crutzen, P. J. (2002). Geology of mankind. Nature, 415(6867), 23.

Dallat, C., Salmon, P. M., \& Goode, N. (2018). Identifying risks and emergent risks across sociotechnical systems: the NETworked hazard analysis and risk management system (NETHARMS). Theoretical Issues in Ergonomics Science, 19(4), 456-482.

Dekker, S.W. 2011. Drift into failure: From hunting broken components to understanding complex systems. Farnham: Ashgate.

Dekker, S. W., Hancock, P. A., \& Wilkin, P. (2013). Ergonomics and sustainability: towards an embrace of complexity and emergence. Ergonomics, 56(3), 357-364.

Elkington, J. (1998). Cannibals with forks: the triple bottom line of 21st century business. Capstone, Oxford.

Elliott, C. (2014). Elliott Review into the integrity and assurance of food supply networks. HM Government, London.

Filho, A.P.G., Jun, G.T. \& Waterson, P.E. (2019). Four studies, two methods, one accident an examination of the reliability and validity of Accimap and STAMP for accident analysis. Safety Science, 113, 310-317.

Fleming, C. H., \& Leveson, N. G. (2016). Early concept development and safety analysis of future transportation systems. IEEE Transactions on Intelligent Transportation Systems, 17(12), 3512-3523.

Fleming, C. H., Spencer, M., Thomas, J., Leveson, N., \& Wilkinson, C. (2013). Safety assurance in NextGen and complex transportation systems. Safety Science, 55, 173-187.

Foster, G. L., Royer, D. L., \& Lunt, D. J. (2017). Future climate forcing potentially without precedent in the last 420 million years. Nature Communications, 8, 14845.

García-Acosta, G., Pinilla, M. H. S., Larrahondo, P. A. R., \& Morales, K. L. (2014).

Ergoecology: fundamentals of a new multidisciplinary field. Theoretical Issues in Ergonomics Science, 15(2), 111-133.

Garner, A. J., Mann, M. E., Emanuel, K. A., Kopp, R. E., Lin, N., Alley, R. B., ... \& Pollard, D. (2017). Impact of climate change on New York City's coastal flood hazard: Increasing flood heights from the preindustrial to 2300 CE. Proceedings of the National Academy of Sciences, 114(45), 11861-11866.

Grant, E., Salmon, P.M., Stevens, N., Goode, N. \& Read, G. (2018). Back to the future: What do accident causation models tell us about accident prediction? Safety Science, 104, 99109. 
Guastello, S. J. (2017). Nonlinear dynamical systems for theory and research in ergonomics. Ergonomics, 60(2), 167-193.

Gunderson, L. H., \& Holling, C. S. (2002). Panarchy: understanding transformations in systems of humans and nature. Island Press, Washington, DC.

Hancock, P. A. (2012). Ergaianomics: The moral obligation and global application of our science. The Ergonomist, 503, 12-14.

Hansen, J., Sato, M., Hearty, P., Ruedy, R., Kelley, M., Masson-Delmotte, V., ... \& Velicogna, I. (2016). Ice melt, sea level rise and superstorms: evidence from paleoclimate data, climate modeling, and modern observations that $2 \mathrm{C}$ global warming could be dangerous. Atmospheric Chemistry and Physics, 16(6), 3761-3812.

Hilliard, A., Tran, F. F., \& Jamieson, G. A. (2018). Work Domain Analysis of power grid operations. In N. A. Stanton, P. M. Salmon, G. H. Walker, \& D. P. Jenkins (Eds.), Cognitive work analysis: applications, extensions and future directions (pp. 151-170). CRC Press, Boca Raton.

Hollnagel, E. (2012). FRAM - The Functional Resonance Analysis Method: Modelling complex socio-technical systems. Farnham, UK: Ashgate.

Intergovernmental Panel on Climate Change (2018, October). Global warming of $1.5^{\circ} \mathrm{C}$. Retrieved from the WWW on 12 October 2018: http://www.ipcc.ch/report/sr15/.

Ishimatsu, T., Leveson, N. G., Thomas, J. P., Fleming, C. H., Katahira, M., Miyamoto, Y., ... $\&$ Hoshino, N. (2014). Hazard analysis of complex spacecraft using systems-theoretic process analysis. Journal of Spacecraft and Rockets, 51(2), 509-522.

Jenkins, D. P., Stanton, N. A., Walker, G. H., Salmon, P. M., \& Young, M. S. (2010). Using cognitive work analysis to explore system flexibility. Theoretical Issues in Ergonomics Science, 11(3), 136-150.

Jiancaro, T., Jamieson, G. A., \& Mihailidis, A. (2014). Twenty years of cognitive work analysis in health care: a scoping review. Journal of Cognitive Engineering and Decision Making, 8(1), 3-22.

Karsh, B-T., Waterson, P.E. \& Holden, R. (2014). Crossing levels in systems ergonomics: a framework to support 'mesoergonomic' inquiry. Applied Ergonomics, 45, 45-54.

Karwowski, W. (2012). A review of human factors challenges of complex adaptive systems: discovering and understanding chaos in human performance. Human factors, 54(6), 983-995. Kelley, C. P., Mohtadi, S., Cane, M. A., Seager, R., \& Kushnir, Y. (2015). Climate change in the Fertile Crescent and implications of the recent Syrian drought. Proceedings of the National Academy of Sciences, 201421533. 
Landrigan, P. J., Fuller, R., Acosta, N. J., Adeyi, O., Arnold, R., Baldé, A. B., ... \& Chiles, T. (2017). The Lancet Commission on pollution and health. The Lancet, 391(10119), 462-512. Lebreton, L., Slat, B., Ferrari, F., Sainte-Rose, B., Aitken, J., Marthouse, R., ... \& Noble, K. (2018). Evidence that the Great Pacific Garbage Patch is rapidly accumulating plastic. Scientific Reports, 8(1), 4666.

Leveson, N. (2004). A new accident model for engineering safer systems. Safety Science, 42(4), 237-270.

Leveson, N. (2015). A systems approach to risk management through leading safety indicators. Reliability Engineering \& System Safety, 136, 17-34.

Li, C., Tang, T., Chatzimichailidou, M.M., Jun, G.T. and Waterson, P.E. (2019, in press). A hybrid human and organisational analysis method for railway accidents based on HFACS STAMP and human cognitive behaviour. Applied Ergonomics.

Lu, Y., Zhang, S. G., Tang, P., \& Gong, L. (2015). STAMP-based safety control approach for flight testing of a low-cost unmanned subscale blended-wing-body demonstrator. Safety Science, 74, 102-113.

Luhmann, N. (1985). A sociological theory of law ( $1^{\text {st }}$ Ed.). New York: Routledge and Kegan Paul plc.

Lundberg, J., Arvola, M., Westin, C., Holmlid, S., Nordvall, M., \& Josefsson, B. (2018). Cognitive work analysis in the conceptual design of first-of-a-kind systems - designing urban air traffic management. Behaviour \& Information Technology, 37(9), 904-925. Mauerhofer, V. (2008). 3-D sustainability: An approach for priority setting in situation of conflicting interests towards a sustainable development. Ecological Economics, 64(3), 496506.

Montzka, S. A., Dutton, G. S., Yu, P., Ray, E., Portmann, R. W., Daniel, J. S., ... \& Nance, J. D. (2018). An unexpected and persistent increase in global emissions of ozone-depleting CFC-11. Nature, 557(7705), 413.

Moray, N. (1995). Ergonomics and the global problems of the twenty-first century. Ergonomics, 38(8), 1691-1707.

Moray, N. (2000). Culture, politics and ergonomics. Ergonomics, 43(7), 858-868.

Naikar, N., \& Elix, B. (2016). Integrated system design: Promoting the capacity of sociotechnical systems for adaptation through extensions of cognitive work analysis. Frontiers in Psychology, 7, 962. 
Naikar, N., Moylan, A., \& Pearce, B. (2006). Analysing activity in complex systems with cognitive work analysis: concepts, guidelines and case study for control task analysis.

Theoretical Issues in Ergonomics Science, 7(4), 371-394.

Nayak, R., \& Waterson, P. (2016). 'When Food Kills': A socio-technical systems analysis of the UK Pennington 1996 and 2005 E. coli O157 Outbreak reports. Safety Science, 86, 36-47. Nayak, R., \& Waterson, P. (2019). Global food safety as a complex system: Key concepts and future prospects. Unpublished Manuscript, Loughborough University.

Nyman, M. R., \& Johansson, M. (2015). Merits of using a socio-technical system perspective and different industrial accident investigation methods on accidents following natural hazards - a case study on pluvial flooding of a Swedish railway tunnel 2013. International Journal of Disaster Risk Reduction, 13, 189-199.

Ottino, J. M. (2004). Engineering in complex systems. Nature, 427, 399

Ouyang, M., Hong, L., Yu, M. H., \& Fei, Q. (2010). STAMP-based analysis on the railway accident and accident spreading: Taking the China-Jiaoji railway accident for example. Safety Science, 48(5), 544-555.

Patz, J. A., Frumkin, H., Holloway, T., Vimont, D. J., \& Haines, A. (2014). Climate change: challenges and opportunities for global health. JAMA, 312(15), 1565-1580.

Pennington, T. H. (2003). When food kills: BSE, E. coli and disaster science ( $1^{\text {st }}$ Ed.).

Oxford: Oxford University Press.

Porter, C. M. (2016). Revisiting Precede-Proceed: A leading model for ecological and ethical health promotion. Health Education Journal, 75(6), 753-764.

Procter, R.W. \& Van Zandt, T. (2018). Human factors in simple and complex systems. (3 ${ }^{\text {rd }}$ Edition). Boca Raton: CRC Press.

Rasmussen, J. (1985). The role of hierarchical knowledge representation in decision making and system management. IEEE Transactions on Systems, Man, \& Cybernetics, 15(2), 234243.

Rasmussen, J. (1997). Risk management in a dynamic society: A modelling problem. Safety Science, 27(2), 183-213.

Read, G. J., Salmon, P. M., Lenné, M. G., \& Jenkins, D. P. (2015). Designing a ticket to ride with the cognitive work analysis design toolkit. Ergonomics, 58(8), 1266-1286.

Read, G. J., Salmon, P. M., Lenné, M. G., \& Stanton, N. A. (2016). Walking the line: understanding pedestrian behaviour and risk at rail level crossings with cognitive work analysis. Applied Ergonomics, 53, 209-227. 
Rigaud, K. K., de Sherbinin, A., Jones, B., Bergmann, J., Clement, V., Ober, K., ... \& Midgley, A. (2018). Groundswell: preparing for internal climate migration. World Bank, Washington.

Rocha, L. (1999). Complex systems modeling: Using metaphors from nature in simulation and scientific models. BITS: Computer and Communications News, Computing. Information and Communications Divisions, November 1999. Retrieved January 21, 2017 from the WWW: https://Www.informatics.indiana.edu/rocha/publications/complex/csm.html.

Rong, H., \& Tian, J. (2015). STAMP-based HRA considering causality within a sociotechnical system: a case of Minuteman III missile accident. Human Factors, 57(3), 375396.

Rosenzweig, C., Karoly, D., Vicarelli, M., Neofotis, P., Wu, Q., Casassa, G., ... \& Tryjanowski, P. (2008). Attributing physical and biological impacts to anthropogenic climate change. Nature, 453(7193), 353.

Rosewater, D., \& Williams, A. (2015). Analyzing system safety in lithium-ion grid energy storage. Journal of Power Sources, 300, 460-471.

Salmon, P. M., Cornelissen, M., \& Trotter, M. J. (2012). Systems-based accident analysis methods: A comparison of Accimap, HFACS, and STAMP. Safety Science, 50(4), 11581170.

Salmon, P. M., Walker, G. H., M. Read, G. J., Goode, N., \& Stanton, N. A. (2017). Fitting methods to paradigms: are ergonomics methods fit for systems thinking? Ergonomics, 60(2), 194-205.

Samir, K. C., \& Lutz, W. (2017). The human core of the shared socioeconomic pathways: Population scenarios by age, sex and level of education for all countries to 2100. Global Environmental Change, 42, 181-192.

Simon, H. A (1962). The architecture of complexity. Proceedings of the American Philosophical Society, 106(6), 467-482.

Sinha, E., Michalak, A. M., \& Balaji, V. (2017). Eutrophication will increase during the 21st century as a result of precipitation changes. Science, 357(6349), 405-408.

Sobel, A. H., Camargo, S. J., Hall, T. M., Lee, C. Y., Tippett, M. K., \& Wing, A. A. (2016). Human influence on tropical cyclone intensity. Science, 353(6296), 242-246.

Stanton, N. A., Salmon, P. M., \& Walker, G. H. (2018). Systems thinking in practice. CRC Press, Boca Raton. 
Stanton, N. A., Salmon, P. M., Rafferty, L. A., Walker, G. H., Baber, C., \& Jenkins, D. P. (2013). Human factors methods: a practical guide for engineering and design (2nd Ed.). Ashgate, Farnham.

Steffen, W., Grinevald, J., Crutzen, P., \& McNeill, J. (2011). The Anthropocene: conceptual and historical perspectives. Philosophical Transactions of the Royal Society of London A: Mathematical, Physical and Engineering Sciences, 369(1938), 842-867.

Steffen, W., Rockström, J., Richardson, K., Lenton, T. M., Folke, C., Liverman, D., ... \& Donges, J. F. (2018). Trajectories of the Earth System in the Anthropocene. Proceedings of the National Academy of Sciences, 201810141.

Stevens, N. J., Salmon, P. M., \& Taylor, N. (2018). Work domain analysis applications in urban planning: Active transport infrastructure and urban corridors. In N. A. Stanton, P. M. Salmon, G. H. Walker, \& D. P. Jenkins (Eds.), Cognitive work analysis: applications, extensions and future directions (pp. 285-302). CRC Press, Boca Raton.

Svedung, I., \& Rasmussen, J. (2002). Graphic representation of accident scenarios: Mapping system structure and the causation of accidents. Safety Science, 40(5), 397-417.

Tabibzadeh, M., \& Meshkati, N. (2015). Applying the AcciMap methodology to investigate a major accident in offshore drilling: A systematic risk management framework for oil and gas industry. In SPE Western Regional Meeting. Society of Petroleum Engineers.

Tabibzadeh, M., Stavros, S., Ashtekar, M. S., \& Meshkati, N. (2017). A systematic framework for root-cause analysis of the Aliso Canyon gas leak using the AcciMap methodology: Implication for underground gas storage facilities. Journal of Sustainable Energy Engineering, 5(3), 212-242.

Thatcher, A. (2013). Green ergonomics: definition and scope. Ergonomics, 56(3), 389-398. Thatcher, A. (2016). Longevity in a sustainable human factors and ergonomics system-ofsystems. 22nd Semana de Salud Occupacional in Medellin, Colombia.

Thatcher, A., \& Yeow, P. H. P. (2016). A sustainable system of systems approach: A new HFE paradigm. Ergonomics, 59(2), 167-178.

Thatcher, A. \& Yeow, P.H.P. (2018). A sustainable system-of-systems approach: identifying the important boundaries for a target system in human factors and ergonomics. In A. Thatcher \& P. H. P. Yeow (Eds.). Ergonomics and human factors for a sustainable future: current research and future possibilities (pp. 23-45). Singapore: Palgrave-MacMillan.

Thatcher, A. \& Yeow, P. H. P. (in press). Factors to consider in the application of the sustainable system-of-systems model for human factors and ergonomics interventions. In A. 
Thatcher, K. J. Zink \& K. Fischer (Eds.). Human factors for sustainability: Theoretical perspectives and global applications. Boca Raton: CRC Press.

Thatcher, A., Waterson, P., Todd, A., \& Moray, N. (2018). State of Science: ergonomics and global issues. Ergonomics, 61(2), 197-213.

Turner, B.A. (1978). Man-made disasters (1st Edition). London: Wykeham Science Press. Underwood, P. \& Waterson, P.E. (2014). Systems thinking, the Swiss Cheese model and accident analysis: a comparative systems analysis of the Grayrigg train derailment using the ATSB, Accimap and STAMP models. Accident Analysis and Prevention, 68, 75-94. Underwood, P., Waterson, P., \& Braithwaite, G. (2016). 'Accident investigation in the wild' A small-scale, field-based evaluation of the STAMP method for accident analysis. Safety Science, 82, 129-143.

Vicente, K. J. (1999). Cognitive Work Analysis: toward safe, productive, and healthy computer-based work. Lawrence Erlbaum Associates, Mahwah, NJ.

Walker, G. H.; Beevers, L., \& Strathie, A. (2018). Using CWA to understand and enhance infrastructure resilience. In N. A. Stanton, P. M. Salmon, G. H. Walker, \& D. P. Jenkins (Eds.), Cognitive work analysis: applications, extensions and future directions (pp. 403-418). CRC Press, Boca Raton.

Walker, G. H., Salmon, P. M., Bedinger, M., \& Stanton, N. A. (2017). Quantum ergonomics: shifting the paradigm of the systems agenda. Ergonomics, 60(2), 157-166.

Waterson. P. E., Robertson, M. M., Cooke, N. J. Militello, L, Roth, E. \& Stanton, N. A. (2015). Defining the methodological challenges and opportunities for an effective science of sociotechnical systems and safety. Ergonomics, 58(4), 650-8.

Waterson, P., Jenkins, D. P., Salmon, P. M., \& Underwood, P. (2017). 'Remixing Rasmussen': The evolution of Accimaps within systemic accident analysis. Applied Ergonomics, 59, 483-503.

Wilson, J. R. (2014). Fundamentals of systems ergonomics/human factors. Applied Ergonomics, 45(1), 5-13.

Woo, D. M., \& Vicente, K. J. (2003). Sociotechnical systems, risk management, and public health: comparing the North Battleford and Walkerton outbreaks. Reliability Engineering \& System Safety, 80(3), 253-269.

Woods, F. (2017). Food fraud report. NFU Mutual, Stratford-upon-Avon.

Zink, K. J., \& Fischer, K. (2013). Do we need sustainability as a new approach in human factors and ergonomics? Ergonomics, 56(3), 348-356. 
Table 1. Complexity of inter-related systems showing human and environmental consequences of asymmetries.

\begin{tabular}{|c|c|c|}
\hline Problems & Human consequences & $\begin{array}{c}\text { Environmental } \\
\text { consequences }\end{array}$ \\
\hline $\begin{array}{l}\text { Resources asymmetries: } \\
\text { Water, food, land, sanitation, energy, } \\
\text { housing, education, jobs, healthcare, } \\
\text { cultural expression }\end{array}$ & $\begin{array}{l}\text { Poverty, hunger, disease, } \\
\text { cultural subjugation and } \\
\text { intolerance, exploitative } \\
\text { labour practices }\end{array}$ & $\begin{array}{l}\text { Land degradation, } \\
\text { drought, deforestation, } \\
\text { water pollution, } \\
\text { monocultures, genetically- } \\
\text { modified organisms }\end{array}$ \\
\hline $\begin{array}{l}\text { Asymmetries in accumulation and } \\
\text { distribution of waste: } \\
\mathrm{CO}_{2}, \mathrm{CO}, \mathrm{O}_{3} \text { depletion, volatile organic } \\
\text { compounds, heavy metals, plastics; e- } \\
\text { waste, nuclear waste }\end{array}$ & $\begin{array}{l}\text { Food security, health, disease } \\
\text { spread, water security, } \\
\text { sanitation security }\end{array}$ & $\begin{array}{l}\text { Global climate change, } \\
\text { desertification, nitrogen } \\
\text { eutrophication, oceanic } \\
\text { and land dead zones, } \\
\text { ocean garbage patches, } \\
\text { species extinction }\end{array}$ \\
\hline $\begin{array}{l}\text { Legislative asymmetries: } \\
\text { Worker protections, technology transfer, } \\
\text { labour-broking, operational relocation, } \\
\text { work casualization, automisation, free } \\
\text { speech protection }\end{array}$ & $\begin{array}{l}\text { Child labour, modern slave } \\
\text { labour, unequal compensation } \\
\text { for work, job losses, culturally } \\
\text { and anthropometrically } \\
\text { inappropriate technology, } \\
\text { cultural subjugation, social } \\
\text { conflict and war }\end{array}$ & $\begin{array}{l}\text { Land degradation, } \\
\text { freshwater depletion, } \\
\text { unequal global } \\
\text { distribution of waste, } \\
\text { deforestation, poaching }\end{array}$ \\
\hline
\end{tabular}


Table 2. Criteria for assessing the suitability of systems analysis tools for addressing global challenges

\begin{tabular}{l|l}
\hline \multicolumn{2}{l}{ Requirement } \\
\hline 1 & Human goals beyond accident prevention \\
\hline 2 & Applied to global challenges \\
\hline 3 & Non-human agents/actors included \\
\hline 4 & Hierarchical nestedness of systems \\
\hline 5 & Enables predictive assumptions \\
\hline 6 & Copes with dynamic, adaptive, self-organising systems thinking \\
\hline 7 & Embraces emergent properties \\
\hline 8 & Links between system elements (i.e. revolt and remember) \\
\hline 9 & Pacing of system transitions considered (e.g. more complex systems are slower to change) \\
\hline
\end{tabular}


Table 3. Comparison of the main HFE systems' analysis tools to address global challenges.

\begin{tabular}{|c|c|c|c|}
\hline & Accimap & STAMP & CWA \\
\hline Goal/s & $\begin{array}{l}\text { Mostly accident } \\
\text { analysis }\end{array}$ & $\begin{array}{l}\text { Mostly accident } \\
\text { analysis }\end{array}$ & $\begin{array}{l}\text { Identify system constraints; } \\
\text { Team interaction; First-of-kind } \\
\text { system evaluation }\end{array}$ \\
\hline $\begin{array}{l}\text { 1. Human goals beyond accident } \\
\text { prevention }\end{array}$ & Partially & Partially & Yes \\
\hline 2. Applied to global challenges & Limited & Limited & Yes \\
\hline $\begin{array}{l}\text { 3. Non-human agents/actors } \\
\text { included }\end{array}$ & Yes & Yes & Yes \\
\hline $\begin{array}{l}\text { 4. Hierarchical nestedness of } \\
\text { systems }\end{array}$ & Yes & Yes & Yes \\
\hline 5. Enables predictive assumptions & Not easily & Yes & Yes \\
\hline $\begin{array}{l}\text { 6. Copes with dynamic, adaptive, } \\
\text { self-organising systems thinking }\end{array}$ & No & No & $\begin{array}{l}\text { Yes, but still requires extensions } \\
\text { such as WOP. }\end{array}$ \\
\hline 7. Embraces emergent properties & No & No & No \\
\hline $\begin{array}{l}\text { 8. Links between system elements } \\
\text { (i.e. revolt and remember) }\end{array}$ & $\begin{array}{l}\text { Control and } \\
\text { communication }\end{array}$ & $\begin{array}{l}\text { Control (two- } \\
\text { way } \\
\text { communication) }\end{array}$ & Means-ends \\
\hline 9. Pacing of system transitions & No & No & No \\
\hline
\end{tabular}


Table 4. Differences in the findings identified by Accimap and STAMP analyses

\begin{tabular}{|c|c|c|}
\hline Characteristic & Accimap & STAMP \\
\hline Purpose and human goals & Not specified & $\begin{array}{l}\text { Production and distribution of } \\
\text { food with integrity and safety for } \\
\text { consumption. }\end{array}$ \\
\hline $\begin{array}{l}\text { Hierarchical nestedness of } \\
\text { systems levels }\end{array}$ & $\begin{array}{l}\text { Presence of systemic levels, each } \\
\text { having a defined role to play in } \\
\text { the efficient functioning of the } \\
\text { food system. }\end{array}$ & $\begin{array}{l}\text { Presence of systemic levels in the } \\
\text { food system, and stakeholders } \\
\text { within each of these levels where } \\
\text { each stakeholder has a role to play } \\
\text { in the production and operational } \\
\text { stages. } \\
\text { Presence of defined controls and } \\
\text { constraints to aid in the efficient } \\
\text { functioning of the food system. }\end{array}$ \\
\hline Links between system elements & $\begin{array}{l}\text { Does not identify specific types of } \\
\text { communications and flow, } \\
\text { however, it does provide the } \\
\text { reader an outlook on whether } \\
\text { there is positive or negative } \\
\text { information flowing between and } \\
\text { within systemic levels. The aim of } \\
\text { this analysis was to highlight } \\
\text { negative information flow leading } \\
\text { to fraudulent behaviour in the } \\
\text { food industry (e.g., prioritisation } \\
\text { of enforcement } \rightarrow \text { prioritisation of } \\
\text { audits } \rightarrow \text { incentives for illegal acts } \\
\rightarrow \text { noncompliance } \rightarrow \text { food fraud). } \\
\text { The Accimap analysis also } \\
\text { highlighted the impact of each } \\
\text { subsystem on the other, and the } \\
\text { resultant behaviours. }\end{array}$ & $\begin{array}{l}\text { Identifies the types of } \\
\text { communications, controls, and } \\
\text { constraints of these } \\
\text { communications, individual } \\
\text { stakeholders involved in } \\
\text { communicating information, and } \\
\text { the responsibilities entrusted upon } \\
\text { them to pass on communication } \\
\text { and receive feedback. }\end{array}$ \\
\hline Emergence & $\begin{array}{l}\text { Identifies top-down as well as } \\
\text { bottom-up interactions between } \\
\text { various stakeholders of the food } \\
\text { system. } \\
\text { The Accimap also identified } \\
\text { emergent patterns in behaviours as } \\
\text { the Elliot Report reviewed a large } \\
\text { number of food fraud and food } \\
\text { crime incidents in the UK. } \\
\text { Consumer demands also played a } \\
\text { role in leading to fraudulent } \\
\text { behaviours by various } \\
\text { stakeholders of food businesses. }\end{array}$ & $\begin{array}{l}\text { Feedback loops within the } \\
\text { STAMP analysis helped establish } \\
\text { the impact of feedback on } \\
\text { stakeholders higher up the } \\
\text { hierarchical chain in the food } \\
\text { system. } \\
\text { The STAMP analysis also helped } \\
\text { identify top-down as well as } \\
\text { bottom-up interactions between } \\
\text { stakeholders. }\end{array}$ \\
\hline Possible interventions & $\begin{array}{l}\text { Although the Accimap analysis } \\
\text { identified the negative adaptability } \\
\text { of the food system, it failed to } \\
\text { identify all the failed control } \\
\text { mechanisms that led to the food } \\
\text { fraud and food crime incidents. }\end{array}$ & $\begin{array}{l}\text { The STAMP analysis identified } \\
\text { the controls and constraints that } \\
\text { are supposed to be in place in an } \\
\text { ideal scenario. This method helps } \\
\text { the reader establish missing } \\
\text { controls and constraints, and thus, } \\
\text { helps policy makers and other key } \\
\text { stakeholders redesign the food } \\
\text { system to prevent further food } \\
\text { fraud incidents. }\end{array}$ \\
\hline
\end{tabular}


Figure 1. Accimap diagram of food fraud incidents in the UK.

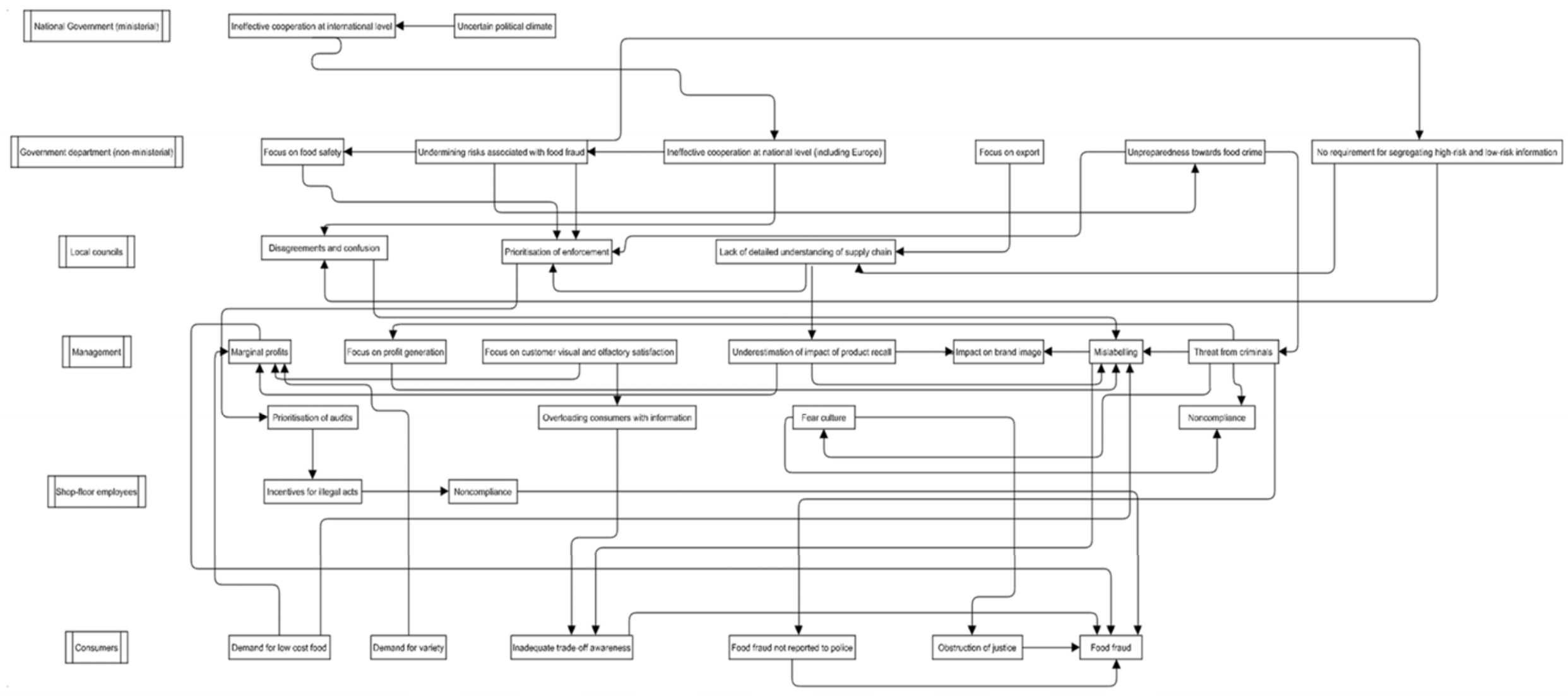


Figure 2. STAMP model of the control and feedback structure of the UK food system adapted from Nayak \& Waterson (2019).

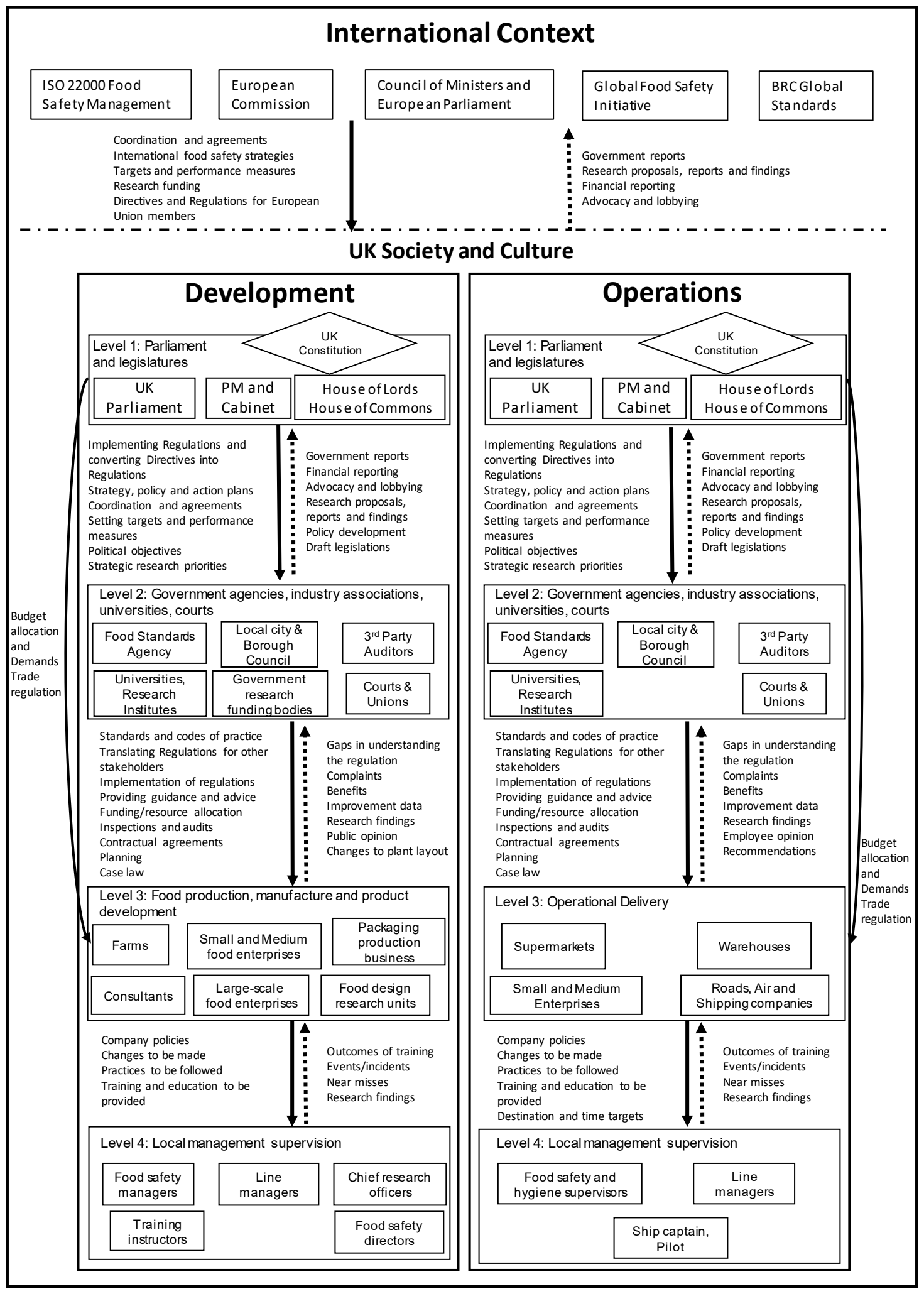

